\title{
MARCUSE E O ALERTA À CONTRARREVOLUÇÃO PREVENTIVA
}

\author{
Robespierre de Oliveira ${ }^{1}$
}

\begin{abstract}
Resumo:
A questão da contrarrevolução foi discutida em vários textos de Marcuse. O objetivo deste artigo é apresentar sua contribuição à elucidação desse problema e sua atualidade. Para Marcuse, a contrarrevolução na sociedade capitalista industrial avançada não se organiza necessariamente em oposição a uma revolução existente, mas sim em oposição à possibilidade de qualquer transformação social para maiores liberdades e direitos, isto é, emancipação social. A contrarrevolução preventiva é um fator na administração do capitalismo tardio para garantia de seu domínio em face das crises econômicas cíclicas. Deste modo, ora esse processo é dissimulado, ora é aberto, com menor ou maior agravamento da violência social. Mesmo atento ao processo de recrudescimento contra as forças de libertação, Marcuse procurava frestas para a emancipação humana. Suas propostas de Grande Recusa e nova sensibilidade visam romper os limites impostos pela dominação existente a partir das necessidades vitais dos próprios indivíduos.
\end{abstract}

Palavras-chaves: Marcuse. Sociedade unidimensional, contrarrevolução, tolerância repressiva, resistência.

\section{MARCUSE AND THE ALERT TO THE PREEMPTIVE COUNTERREVOLUTION}

\begin{abstract}
:
Marcuse discussed the issue of counterrevolution in many texts. The aim of this article is to present his contribution to the elucidation of this problem and its actuality. For Marcuse, counterrevolution in advanced industrial capitalist society is not organized necessarily in opposition to an existent revolution, but in opposition to the possibility of any social change for more liberties and rights, social emancipation. Preemptive counterrevolution is a factor in the administration of late capitalism to the guarantee of its rule in face of cyclical economic crises. This way, sometimes this process is covert, sometimes it is open, with less or more aggravation of social violence. Even in the process of resurgence against the forces of liberation, Marcuse was looking for gaps for human emancipation. His proposals of Great Refusal and new sensibility are aimed at breaking the limits imposed by the existing domination, coming from the vital needs of the individuals themselves.
\end{abstract}

Keywords: Marcuse. One-dimensional society. Counterrevolution. Repressive tolerance. Resistance.

The Western world has reached a new stage of development: now, the defense of the capitalist system requires the organization of counterrevolution at home and abroad. In its extreme manifestations, it practices the horrors of the Nazi regime. Wholesale massacres in Indochina, Indonesia, the Congo, Nigeria, Pakistan, and the Sudan are unleashed against everything which is called "communist" or which is in revolt against governments subservient to the imperialist countries. Cruel persecution prevails in the Latin American countries under fascist and military dictatorships. Torture has become a normal instrument of 'interrogation' around the world. The agony of religious wars revives at the height of Western civilization, and a constant flow of arms from the rich countries to the poor helps to perpetuate the oppression of national and social liberation. (Marcuse, Counterrevolution and Revolt, 1972).

1 Professor Associado da UEM. Doutor em Filosofia da USP. Pós-doutorado na CUNY (City University of New York). Membro da International Herbert Marcuse Society. Tradutor de Marcuse. Autor de O papel da filosofia na teoria crítica de Herbert Marcuse, São Paulo, EdUnesp, 2012. E-mail: roliveira@ uem.br. 
Herbert Marcuse foi um dos primeiros a discutir o problema da contrarrevolução e da contenção na sociedade industrial avançada. Após a Segunda Guerra Mundial, Marcuse elaborou um texto, posteriormente denominado "33 teses", que deveria ser publicado na Revista de Pesquisa Social, a qual já havia sido descontinuada e não retomada. A derrota do Nazifascismo havia sido prometida como a construção de mundo melhor, de mais liberdade e democracia, sem guerras e violência, porém isto não aconteceu. As tensões, principalmente, entre a União Soviética e Estados Unidos levaram a um novo tipo de guerra, a Guerra Fria (1947-1991). Em certo sentido, seria o início de uma era contrarrevolucionária preventiva, contra qualquer possibilidade de libertação, entendida como "comunismo". Para os países capitalistas e sociedades industriais avançadas, a ameaça de comunismo justificava a organização da sociedade para prevenir tal ameaça. O Tratado do Atlântico Norte (OTAN) foi estabelecido em 1949 para este propósito, expandindo o poderio militar dos EUA pelo mundo. A ameaça do comunismo foi combatida na Guerra da Coreia (1950-53) e do Vietnã (1955-75), para mencionar duas guerras conhecidas, e vários golpes militares pelo mundo (como na América Latina) e intervenções militares em muitos países. Em suas "33 teses", Marcuse afirmou

Depois da derrota militar de Hitler e do fascismo (que foi uma forma prematura e isolada de reorganização capitalista), o mundo dividiu-se num campo neofascista e num campo soviético. O que resta das formas democrático-liberais será esmagada entre os dois campos ou absorvida por eles (Marcuse, 1999, p. 217).

Para Stanley Aronowitz, ${ }^{2}$ a predição de Marcuse não teria sido realizado na medida em que se considere o avanço da democracia entre muitos países, incluindo aqueles que foram comunistas. Entretanto, Aronowitz não observa que países que ele menciona como Argentina, México e Brasil se tornaram democráticos após um longo período ditatorial. Muitos países sofreram golpes de Estado enquanto Marcuse estava vivo. O processo democrático nestes países, tanto quanto nos países ex-comunistas, aconteceu muitos anos após sua morte. Mesmo assim, esse processo democrático não chegou a se consolidar efetivamente. Contudo, Aronowitz observa que a concepção de Marcuse de fascismo difere da usual

But consider how Marcuse's conception differs from the accepted views of fascism. Of course, U.S. society is not marked by a program of systematic terror against racialized minorities, although, as we have seen, the number of incidents of police

2 Stanley Aronowitz, The Unknown Marcuse In.: Social Text 58, Vol. 17, No.1, Spring 1999. 133154.

\begin{tabular}{|l|l|l|l|l|}
\cline { 2 - 4 } & Ano 8 & n. 14 & Janeiro-Julho 2019 & p. $15-33$ \\
\hline
\end{tabular}


violations of the rights of black men has escalated in proportion as poverty and unemployment deepens in the cities. But in other respects-such as the intensification of individualism, the decline of the labor movement and other social groups, and the emergence of a cultural environment of puritanical antisexuality-U.S. society has all the earmarks of a growing authoritarianism (Aronowitz, 1999, 152).

Mesmo não considerando a sociedade estadunidense como "fascista", por não ser marcada por um "programa de terror sistemático contra minorias", Aronowitz reconhece que a sociedade dos EUA possua características de um crescente autoritarismo. Marcuse havia percebido isso quando viu frustradas suas propostas e de seus colegas no departamento de Estado dos EUA, a OSS (Office of Strategic Services), para a desnazificação da Alemanha no pós-guerra. Tais propostas incluíam a redemocratização da Alemanha com base na liberdade sindical e apoio a movimento populares. O governo dos EUA preferiu, ao invés, colocar exnazistas de terceiro ou quarto escalão nos governos, coibir movimentos populares e sindicatos, com medo da expansão comunista. Este medo também levou a uma perseguição interna e externa de possíveis comunistas (McCarthyismo). Isto foi obra da Guerra Fria.

Depois da Segunda Guerra, houve muitos movimentos de libertação colonial. Alguns deles tornaram-se países comunistas, como Angola e Moçambique. Os EUA sentiram esta ameaça muito próxima de seu quintal com a revolução cubana (1953-59), que recebeu apoio da União Soviética. Assim, para evitar uma "nova Cuba", os EUA fizeram esforços pela América Latina, com a CIA, apoiando muitas ditaduras militares, incluindo Brasil, Argentina e Chile. Estas ditaduras causaram a morte de milhares de pessoas, tortura, destruíram a cultura, o desenvolvimento e a vida de gerações. Em troca, os EUA expandiram sua cultura, filmes e música, para moldar tais povos pela indústria cultural.

Theodor W. Adorno e Max Horkheimer elaboraram sua crítica a indústria cultural em seu famoso livro A dialética do esclarecimento (1947), mostrando o declínio da arte como fonte de conhecimento e elevação espiritual e seu uso cada vez mais ideológico, reforçando a estrutura de dominação social vigente. No mesmo ano, Horkheimer também publicou o seu Eclipse da Razão, no qual mostrava que a razão ofuscada se tornara instrumental e propicia para a dominação ao invés da emancipação. Marcuse, por sua vez, em Algumas implicações sociais da tecnologia moderna (1941), registrara o poder da tecnologia como meio ideológico de dominação, elaborando o conceito de razão tecnológica. Estas elaborações foram fundamentais para o estudo sobre a contenção da sociedade industrial avançada realizado por Marcuse nos anos 1950 e que veio a lume em O homem unidimensional (1964).

\begin{tabular}{|c|c|c|c|c|}
\cline { 2 - 4 } & Ano 8 & n. 14 & Janeiro-Julho 2019 & p. $15-33$ \\
\hline
\end{tabular}


Em seu livro, Marcuse critica fundamentalmente o caráter ideológico da sociedade unidimensional. Deste modo, critica a proclamação de Daniel Bell do "fim da ideologia" e se opõe a The Warfare State de Fred J. Cook, que trata do poderio bélico estadunidense, e The Hidden Persuaders de Vance Packard, que trata do largo uso da propaganda comercial para a imposição do consumo. O crescimento pós-guerra nos EUA implicou no aumento do consumo de mercadorias, incluindo bens culturais, principalmente por meio da televisão. Nesse período, constituiu-se o que conhecemos como mídia, a conjunção de meios de comunicação, com larga exploração de imagens. Assim, Marcuse denominou sociedade unidimensional a "sociedade da mobilização total, que ganha forma nas mais avançadas áreas da civilização industrial, combina em produtiva união as características do Estado de Bem-Estar Social (Welfare State) e do Estado de Guerra (Warfare State)." (Marcuse, 2015, p. 215) Em certo sentido, para ele tratava-se de fazer uma contrapartida de seu outro livro Soviet Marxism (1958). Marcuse explicou, em carta a Raya Dunaevskaya, autora de Marxism and Freedom (1958), sua intenção de escrever $O$ homem unidimensional, cujo título inicial seria Estudos da Ideologia da Sociedade Industrial Avançada (1958). Eu cito:

I may have told you that my new book with the tentative title Studies in the Ideology of Advanced Industrial Society, is some sort of western counterpart of Soviet Marxism - that is to say it will deal, not only with ideology but also with the corresponding reality. ${ }^{3}$

A negação das ideologias constitui uma ideologia mesma que visa reforçar a estrutura de dominação. Parte desta ideologia reside na linguagem orwelliana ${ }^{4}$ e no caráter afirmativo da cultura, transformada em "dessublimação repressiva". Para Marcuse, o universo do discurso está se fechando. A linguagem é ideologicamente usada para esconder a realidade, frequentemente fingindo e clamando alguma outra coisa. Como "guerra é paz" e "liberdade é escravidão", "ignorância é força", a segurança é uma palavra para garantir liberdade, mas liberdade com mais vigilância, força policial e espionagem. Os indivíduos precisam sentir-se livre ao serem mais e mais isolados no abrigo de suas casas. Os significados políticos das palavras são mudados de acordo com a conveniência daqueles que estão no poder. Deste modo, a democracia totalitária usa a propaganda para glorificar "liberdade", "democracia", "tolerância", "igualdade", entre outras palavras. O significado destas palavras, no entanto, não

3 Carta de Marcuse a Raya Dunayevskaya 8-6-1960 In: Anderson, Kevin and Rockwell, Russell. (eds.) The Dunayevskaya-Marcuse-Fromm Correspondence 1954-1978. Dialogues on Hegel, Marx and Critical Theory. Lanham, Boulder, Lexington, New York, Toronto, Plymouth (UK), Lexington Books, 2012, p. 59. 4 Referência a George Orwell, 1984.

\begin{tabular}{|l|c|c|c|c|}
\hline Rovita Dialectus & Ano 8 & n. 14 & Janeiro - Julho 2019 & p. $15-33$ \\
\hline
\end{tabular}


possui o mesmo conteúdo na realidade do que no discurso. Quando o governo ou a mídia utilizam tais palavras, elas indicam realmente significados diferentes daquele estabelecido na história humana, até opostos. Apesar de proclamar e possuir uma aparência de democracia, o governo estadunidense configura-se mais como um governo autoritário, daí o termo "democracia totalitária", termo já existente na história da filosofia. Refere-se à estrutura democrática, instituições, constituição, eleições, absolutamente coordenada e administrada de tal modo que o povo é apenas um acessório para legitimar decisões já tomadas ou garantir os interesses daqueles que estão no poder. Por meio das eleições, o povo acredita que votou de acordo com seus próprios interesses e consciência, mesmo que não seja verdade. A ascensão de Hitler ao poder, após uma tentativa frustrada de golpe, foi por meio das eleições, o que apareceu ao mundo, na época, como parte do processo democrático. A estrutura política dos EUA acaba por reduzir as campanhas eleitorais a apenas dois partidos que se revezam no poder, por serem os únicos capazes financeiramente de produzir campanhas de massa, em detrimento de todos os demais partidos existentes. Da mesma forma, a elaboração de leis e sua aplicação podem ser restritas a uma camada social embora sejam ditas universais. ("A lei é para todos".)

Edward Bernays, sobrinho de Sigmund Freud, publicou em 1928 o livro Propaganda, que inspirou líderes políticos, como Joseph Goebbels, ministro da Propaganda do III Reich. De acordo com Bernays, as pessoas na sociedade democrática agem, pensam e consomem segundo o que lhes foi dito para agirem, pensarem e consumirem, embora acreditem que seu comportamento, pensamento e consumo seja escolha própria. Há poderes ocultos na sociedade que determinam os hábitos dos indivíduos, como a propaganda e os comerciais. Assim, é possível manipular-se toda uma sociedade. ${ }^{5}$ Goebbels seguiu os princípios de Bernays, criando o inimigo comum, os judeus, para mobilizar a Alemanha em torno da unidade: um só povo, um só império, um só Führer. Tratava-se de um processo de "coordenação" (coordination), palavra que Marcuse utilizou para traduzir o significado de "Gleichschaltung". Segundo Charles Reitz, "A Gleichschaltung era a prática fascista de forçar cada um na sociedade a 'andar na linha' e toda oposição política a se submeter." (Reitz, 2014, p. 3) A total mobilização, promovida pela Gleichschaltung, devia proteger o estado de coisas existente, seja

Entre os exemplos de manipulação promovidos pelo próprio Bernays, podem ser citados o convencimento de bacon e ovos serem parte de um café da manhã saudável, incitar as mulheres a fumarem cigarros como meio de liberdade e autoafirmação, e a destituição do governo da Guatemala em 1954, acusado falsamente de comunista. 
numa visão política ou econômica. Na sociedade industrial avançada, o consumismo é um modo ideológico para mobilizar as pessoas a justificarem para si mesmas o sistema que as oprime.

O consumo de mercadorias determina o comportamento, o pensamento e a sensibilidade dos indivíduos. Os indivíduos realizam sua felicidade, em parte, pelo consumo de mercadorias, como um carro novo, uma roupa nova, pelo tipo de alimentação e bebida, pelos livros, músicas e filmes que consomem. Na medida em que esse consumo atrela os indivíduos ao sistema de dominação, seriam falsas necessidades para além das necessidades básicas. Marcuse afirma a diferença entre necessidades verdadeiras ou falsas.

\footnotetext{
There are 'false' and 'real' needs - the former are those which serve to perpetuate toil, aggressiveness, and the powers that be (such as the need to buy a new automobile every other or third year, the need to relax before television, to work in an armament factory, to eat enriched and soggy bread, the need to "keep up with the neighbors") (Marcuse, 2001, p. 52).
}

O consumo de artefatos tecnológicos ampliou-se para a sociedade industrial avançada de tal modo que as pessoas não sabem mais como viver sem a tecnologia. Segundo Marcuse, em Algumas implicações sociais da tecnologia moderna, a tecnologia não é neutra. Para ele, a tecnologia é entendida como um modo de produção que organiza a vida do todo. Na sua produção, a tecnologia já possui a determinação de seus interesses, é imbuída de ideologia. Isso desenvolve uma racionalidade tecnológica que poderia ser entendida como uma racionalidade derivada do sistema de produção, visando eficiência, produtividade e lucro. A maioria da tecnologia de uso cotidiano veio do uso militar. Para Walter Benjamin, ${ }^{6}$ a realização da tecnologia está na guerra. Assim, sua adaptação à vida social não é neutra, mas organizada, classificada, coordenada, administrada. A racionalidade tecnológica pode combinar a objetividade racional com fins irracionais, como os campos de extermínio nazistas.

Deste modo, para Marcuse, há um vínculo entre o Estado de Guerra e o Estado de Bem-Estar. ${ }^{7}$ Marcuse inicia $\mathbf{O}$ homem unidimensional expressando isto:

Uma não liberdade confortável, muito agradável, racional e democrática prevalece na civilização industrial avançada, um sinal do progresso técnico. Na verdade, o que poderia ser mais racional que a supressão da individualidade na mecanização de performances socialmente necessárias, mas penosas; que a concentração de

6 Benjamin, Walter. "Theories of German Fascism" In New German Critique, trans. Jerolf Wikoff, Spring 1979, n. 17, pp. 120-128.

7 Como no livro 1984 de George Orwell, uma guerra distante é necessária para garantir uma vida pacífica.

\begin{tabular}{|l|l|l|l|l|}
\cline { 2 - 4 } Q & Ano 8 & n. 14 & Janeiro-Julho 2019 & p. $15-33$ \\
\hline
\end{tabular}


empreendimentos individuais em corporações mais efetivas, mais produtivas; que a regulação da livre competição entre sujeitos econômicos desigualmente equipados; que a restrição de prerrogativas e soberanias nacionais que impedem a organização internacional dos recursos. Que este ordenamento tecnológico envolva também uma coordenação política e intelectual pode ser uma evolução lamentável, mas ainda promissora (Marcuse, 2015, p. 41).

A sociedade da total administração, que abrange a vida total dos indivíduos com mídia e propaganda, é um desenvolvimento da racionalidade tecnológica. ${ }^{8}$ Adorno, Hrokheimer e Marcuse escreveram sobre o declínio da individualidade no mundo contemporâneo. Os indivíduos parecem ser parte de um todo na medida em que podem consumir não apenas suas mercadorias, mas também ideais e visões políticas acabadas (ready-made). A mídia colabora nesse processo, distribuindo imagens e formas prontas. Segundo Douglas Kellner, ${ }^{9}$ a cultura mídia é fundamentalmente imagética, ela constrói identidades às quais os indivíduos aderem. Assim, há uma estrutura unilateral, quase totalitária, na sociedade, na medida em que a diversidade é coordenada para se adaptar ao todo. É a sociedade unidimensional.

Esta coordenação (Gleichschaltung) articula o Estado de Bem-Estar com o Estado de Guerra. O Estado de Bem-Estar seria caracterizado tanto pelos benefícios sociais garantidos pelo Estado, como educação, saúde, previdência, seguro desemprego, moradia, entre outros, quanto pela garantia de acesso a bens de consumo. Isso se caracteriza, principalmente, por políticas públicas. Entretanto, o Estado de Bem-Estar foi paulatinamente sendo desmontado em função da política neoliberal, de tal modo que os indivíduos deveriam arcar sozinhos com despesas antes garantidas pelo Estado, como educação e saúde. Assim, a desigualdade econômica aumentou e até o consumo foi reduzido. Este movimento ocorreu nos anos 1970, última década de vida de Marcuse, que mesmo assim anteviu o estava para vir em suas palestras

8 Em "Some Social Implications of Modern Technology", Marcuse dá um exemplo: "A man who travels by automobile to a distant place chooses his route from the highway maps. Towns, lakes and mountains appear as obstacles to be bypassed. The countryside is shaped and organized by the highway: what one finds en route is a byproduct or annex of the highway. Numerous signs and posters tell the traveler what to do and think; they even request his attention to the beauties of nature or the hallmarks of history. Others have done the thinking for him, and perhaps for the better. Convenient parking spaces have been constructed where the broadest and most surprising view is open. Giant advertisements tell him when to stop and find the pause that refreshes. And all of this is indeed for his benefit, safety and comfort; he receives what he wants. Business, technics, human needs and nature are welded together into one rational and expedient mechanism. He will fare best who follows its directions, subordinating his spontaneity to the anonymous wisdom which ordered everything for him." In Marcuse, Technology, War and Fascism, p. 46.

${ }^{9}$ Kellner, Douglas. Media Culture. Cultural Studies, Identity and Politics between the Modern and Postmodern. London and New York, Routledge, 1995.

\begin{tabular}{|c|c|c|c|c|}
\hline Gevista Dialectus & Ano 8 & n. 14 & Janeiro-Julho 2019 & p. $15-33$ \\
\hline
\end{tabular}


dadas em Vincennes. ${ }^{10}$ Por outro lado, o Estado de Guerra foi fortalecido. Após a Segunda Guerra, os EUA configuraram-se em potência militar expandindo-se mundialmente. O confronto com a URSS, a Guerra Fria, produziu uma espécie de corrida bélica. Houve conflitos e guerras localizadas, como a da Coreia e do Vietnã. ${ }^{11}$ O Estado de Guerra busca mobilizar a sociedade ressaltando o patriotismo e a necessidade de segurança interna e externa. Assim, cursos universitários eram voltados para a indústria bélica. Para a Guerra do Vietnã, havia sorteios de convocação ao vivo na TV. A mesma TV mostrou os horrores da guerra o que iniciou um movimento contrário à guerra. A sociedade mobilizou-se em grupos a favor e contra, resultando no fim da guerra nos anos 1970. A mobilização do Estado de Guerra também aparece na esfera interna do Estado, com vigilância e mesmo em termos policiais. E o Pentágono parece ter adquirido uma autonomia em relação ao presidente dos EUA, o que configuraria o Deep State. Assim, o Estado de Guerra manteve-se e continua forte até hoje espalhado pelo mundo, nas guerras do Iraque, nos ataques da OTAN, na guerra contra o terrorismo.

Certamente, o Estado de Guerra é peça fundamental à contrarrevolução, dividindose na atuação da CIA e das forças armadas. Ele teve papel fundamental em golpes de Estado na América Latina e em outros continentes. Apoiou iniciativas contra a Revolução Cubana e Nicaraguense, invadiu Granada. Marcuse chegou a afirmar em suas Palestras em Vincennes que o Pentágono seria uma grande empresa única

No longer only by way of the subsidies directly or indirectly, but the government itself has become directly a major economic unit. The Pentagon in the United States today is the biggest single industrial enterprise (Marcuse In.: Jansen e Reitz, 2015, p. 40).

É de se notar que Marcuse também se refere ao próprio governo como uma unidade econômica. Sheldom Wolin escreveu Politics and Vision em 1960, livro que possui afinidades com Marcuse, ${ }^{12}$ embora Wolin seja liberal. Particularmente, Wolin afirma a existência de

10 Ver JANSEN, Peter-Erwin and REITZ, Charles. (eds) Herbert Marcuse's 1974 Paris Lectures at Vicennes University from Marcuse Archives. Global Capitalism and Radical Opposition. Introduction by Sarah Surak and afterwords by Douglas Kellner. Maryland USA, Salisbury University, 2015. Ver também meu comentário "Globalização, Contrarrevolução e Nova Sensibilidade: Leitura Das Palestras De Paris De 1974 de Marcuse" In: Piracicaba, Comunicações, maio-agosto de 2017, v. 24, n. 2, pp. 127-136.

11 Segundo Chomsky, criou-se o "sistema do Pentágono", que teria força e uma certa autonomia para enfrentar o inimigo externo. Durante a Guerra Fria, esse inimigo comum era o comunismo; após, somente em fins dos anos 1990, o "terrorismo islâmico" foi eleito em substituição ao comunismo como tal inimigo (Chomsky, 1991).

12 Ver Maley, Terry. "Human Emancipation and The Historical Fate Bourgeois Democracy" In Maley, Terry (ed.) One-dimensional Man 50 years on: The Struggle Continues, Nova Scotia,

\begin{tabular}{|c|c|c|c|c|}
\hline Q Rovista Dialectus & Ano 8 & n. 14 & Janeiro-Julho 2019 & p. 15 - 33 \\
\hline
\end{tabular}


superpoderes que ameaçam a estrutura democrática, a qual seria fugidia. De fato, segundo ele, as empresas tomam o poder do Estado e controlam o governo de tal modo que o cidadão não teria o mesmo poder. Segundo Wolin,

\begin{abstract}
The modern regime, regardless of form, is shaped by the need to maintain continuous functions: promotion of the economy, law enforcement, military preparedness, revenue collection, protection and control of systems of communication. It is a design for administration rather than democracy. When democracy is settled into a stable form, such as prescribed by a written constitution, it is also settled down and rendered predictable. Then it becomes the stuff of manipulation: of periodic elections that are managed and controlled, of public opinion that is shaped, cajoled, misled, and then polled, and of a legal system that dictates how much democracy is to be permitted (Wolin, 2004, p.601)
\end{abstract}

Esta visão aproxima-se daquela de Horkheimer, Adorno e Marcuse segundo a qual o governo é tomado por uma máfia (rackets). A democracia totalitária, como dito acima, atua na manipulação popular mantendo a ilusão democrática. Marcuse, em suas Palestras de Vincennes, afirma que a desintegração da burguesia como poder dominante leva a uma indiferenciação entre negócios legais e ilegais. ${ }^{13}$ Eu cito:

\begin{abstract}
At the same time I think we can observe in the United States a phenomenon of great importance which I would like to call the decomposition, even disintegration, of the bourgeoisie as a dominant class. Of course, the bourgeoisie still is the dominant class, but as such it has undergone significant changes. The difference between legitimate and illegitimate business is constantly being obfuscated, and the economic and political power of the so-called Mafia extends itself to all branches of economic and political life (Marcuse In Jansen e Reitz, 2015, p. 2).
\end{abstract}

Se esta teoria é correta, poderíamos pensar que os agentes políticos agem como a máfia agia no começo do século XX. Lucky Luciano e Al Capone foram responsáveis por estabelecer a máfia nos EUA. Eles adotaram métodos de organização capitalista para gerenciamento de suas atividades combinados com violência. Assim, eles possuíam uma imagem pública respaldada por agentes públicos comprados, policiais, juízes e políticos. Al Capone, inclusive, ajudava populações carentes com doações, o que melhorava sua imagem. Viviam luxuosamente entre a high society. Ao mesmo tempo, massacravam seus opositores e

Manitoba, Fernwood Publishing, 2017. Neste artigo, Maley discute a relação de Wolin e Marcuse, entre outros.

${ }^{13}$ Poderíamos pensar a intermediação entre empresas e políticos, principalmente por meio de trocas de favores, corrupção, como parte desse processo. Atualmente, há o caso de empresas que se promovem politicamente a ponto de não necessitarem mais de intermediação.

\begin{tabular}{|l|l|l|l|l|}
\hline Qevista Qialectus & Ano 8 & n. 14 & Janeiro-Julho 2019 & p. $15-33$ \\
\hline
\end{tabular}


quem não cumpria seus desígnios. A máfia institucionalizada agiria de forma semelhante, sendo a violência executada de forma legal por agentes do Estado, e, quando não, seria acobertada "legalmente".

A violência é parte da estrutura do Estado. Não há propriamente interesse em acabar com a violência, mas administrá-la. Policiais, por vezes, chegam a ser mais violentos que os civis abordados por eles, sejam criminosos ou não. Nos EUA, como em outros países, a discriminação racial tende ao racismo, velado ou não, em que negros são tratados como culpados a priori. ${ }^{14}$ Contra o segregacionismo, Martin Luther King Jr., entre outros, liderou o movimento por direitos civis nos anos 1960, que, mesmo após conquistas significativas, continua ainda hoje sendo causa importante entre os negros que ainda não conseguiram plenamente seu reconhecimento social. A violência contra mulheres, indígenas, LGBTQs, possui um movimento semelhante de segregação, desigualdade social, e luta por direitos.

Marcuse advogou contra a violência, tanto contra as mulheres, negros, quanto contra a violência da guerra. Mas ele não defendia a não-violência frente aos ataques de agentes do Estado, mas a contra-violência, isto é, o direito de se defender se for atacado. Marcuse assinala que se exige a não violência dos mais fracos. Eu cito:

\begin{abstract}
Even in the advanced centers of civilization, violence actually prevails; it is practiced by the police, in the prisons and mental institutions, in the fight against racial minorities; it is carried, by the de- fenders of metropolitan freedom, into the backward countries. This violence indeed breeds violence. But to refrain from violence in the face of vastly superior violence is one thing, to renounce a priori violence against violence, on ethical or psychological grounds (because it may antagonize sympathizers) is another. Non-violence is normally not only preached to but exacted from the weak - it is a necessity rather than a virtue, and normally it does not seriously harm the case of the strong (Marcuse, 1965, p. 102).
\end{abstract}

Assim, estes ficam sujeitos à violência praticada na sociedade. O Estado liberal pressupõe a proteção dos vulneráveis, daí a ênfase nos direitos humanos. Entretanto, geralmente isto não ocorre. Suprime-se o outro, como a questão do encarceramento massivo de negros nos EUA, que gera lucros para presídios privados. Para Marcuse, não se pode considerar como igual a violência de nazistas e racistas e a contra-violência de seus opositores. Não há equivalência dos "dois lados". A tolerância repressiva supõe tolerar aqueles que são contra os direitos

1450 anos após a marcha pelos direitos civis de Selma a Montgomery, os afro-americanos ainda lutam por igualdade e reconhecimento. O movimento “Black Lives Matter", surgido após as mortes de Mike Brown e Eric Garner pela polícia, iniciou uma nova onda pelos direitos civis.

\begin{tabular}{|l|c|c|c|c|}
\hline Rovista Q Palectus & Ano 8 & n. 14 & Janeiro-Julho 2019 & p. $15-33$ \\
\hline
\end{tabular}


humanos, contra as "minorias", contra os diferentes, contra a democracia, contra o que é universalmente ético. ${ }^{15}$

É de se observar como a mídia insufla casos de violência criando uma espécie de paranoia em que as pessoas buscam soluções individuais, como transformar a casa num tipo de bunker, com cerca elétrica, câmaras, ou se armar. A sensibilidade dos indivíduos é afetada e direcionada para a agressividade. $\mathrm{O}$ fascismo aproveita-se desta situação ao apontar um inimigo comum em defesa dos cidadãos "de bem". Segundo Erich Fromm, os homens ${ }^{16}$ possuem medo da liberdade, por serem extremamente dependentes. Os homens preferem submeter-se a uma autoridade, seja de Deus, do governo, ou quem for do que se virarem sozinhos. Eu cito:

\footnotetext{
They [People] cannot go on bearing the burden of "freedom from"; they must try to escape from freedom altogether unless they can progress from negative to positive freedom. The principal social avenues of escape in our time are the submission to a leader, as has happened in Fascist countries, and the compulsive conforming as is prevalent in our own democracy (Fromm, 2001, pp. 115/116).
}

O anseio por líderes ou conformidade aos poderes estabelecidos na sociedade "democrática", instituições, o anseio por autoridade, faria parte de um aspecto infantil dos seres humanos que possuem medo de serem livres e autônomos, ao mesmo tempo em que querem a aparência de liberdade. Em Obsolescence of Psychoanalysis (1963), Marcuse mostra como a deficiência na constituição do ego nos indivíduos da família contemporânea produziria o enfraquecimento da figura do pai, a qual seria de vital importância para a psique do indivíduo segundo Freud. Uma sociedade sem pai seria psicótica, podendo facilitar governos autoritários. Assim, líderes como Stálin e Hitler buscavam se colocar como "pais" da nação. Entretanto, líderes, autoritários ou não, nem sempre correspondem à figura do pai, mesmo que posem como se fossem. Alguns nem chegam à figura do "grande irmão".

O controle social da liberdade ("aparência de liberdade") torna-se fundamental na sociedade unidimensional. Parte da ilusão de liberdade consiste na possibilidade de escolher entre objetos previamente determinados, a escolha é limitada. Assim, escolhe-se produtos no mercado, estilos de música, filmes, livros, roupas, políticos e partidos, etc. E, geralmente, no fundo, não há muita diferença entre os objetos a escolher. O controle da liberdade ocorre

15 Nos EUA, alguns grupos invocam o direito de liberdade de religião para não aceitar receber, servir, ou reconhecer, homossexuais.

16 "Homens" referem-se a todos os seres humanos por força da linguagem, isto é, as mulheres também estão incluídas aí.

\begin{tabular}{|l|l|l|l|c|}
\cline { 2 - 4 } Govita & Ano 8 & n. 14 & Janeiro - Julho 2019 & p. $15-33$ \\
\hline
\end{tabular}


principalmente quando os indivíduos passam a querer mais do que lhes é ofertado, quando demandam direitos e reconhecimento. ${ }^{17}$ A sociedade unidimensional busca pressionar os indivíduos a padrões estabelecidos. A democracia totalitária funciona com o controle de quanta liberdade o povo deveria ter, dando-lhes o que é necessário para manter o establishment. Mesmo em que em certos períodos ceda e reconheça novos direitos dando mais liberdade aos indivíduos, em outros períodos não vacila em reprimir essa liberdade se for considerada ameaça ao establishment. Segundo Marcuse,

À negação da liberdade, até mesmo da possibilidade de liberdade, corresponde a concessão de liberdades quando elas fortalecem a repressão. A medida em que à população é permitido romper a paz onde quer que ainda haja paz e silêncio, ser feia e enfeiar as coisas, abusar da familiaridade, ofender a boa forma é assustadora. É assustadora porque expressão esforço lícito e mesmo organizado para rejeitar o Outro em seu próprio direito, para impedir a autonomia até mesmo numa esfera pequena e reservada da existência. Nos países superdesenvolvidos, uma parte cada vez maior da população se torna uma audiência cativa - capturada não por um regime totalitário, mas pelas liberdades dos cidadãos cuja mídia de entretenimento e elevação obriga o Outro a participar de seus, sons, visões e cheiros (Marcuse, 2015, p. 230).

E mais adiante:

Sem dúvida, tal situação seria um pesadelo insuportável. Se por um lado as pessoas podem suportar a produção contínua de armas nucleares, partículas radioativas e gêneros alimentícios questionáveis, por outro, elas não podem (pela mesma razão!) tolerar serem privadas do entretenimento e da educação que as tornam capazes de reproduzir as disposições para sua defesa e/ou destruição. O não-funcionamento da televisão e da mídia do mesmo tipo pode assim começar a atingir o que as contradições inerentes do capitalismo não puderam - a desintegração do sistema. A criação de necessidades repressivas desde há muito tem se tornado parte do trabalho socialmente necessário - necessário no sentido de que sem ele o modo estabelecido de produção não poderia ser sustentado. Não são os problemas da psicologia nem os da estética que estão em jogo, mas sim a base material da dominação (Marcuse, 2015, 231).

A pressão econômica e social que se faz sobre os indivíduos, os leva a se isolarem e demandarem segurança, pensando em seus próprios interesses imediatos. Em certo sentido, isso explicaria a ascensão de Hitler ao poder, entre outros. Por volta de 1972, Marcuse escreveu The Historical Fate of Bourgeois Democracy, analisando as eleições dos EUA que levaram Richard Nixon ao poder. Ele repete sua afirmação das "33 Teses". Para ele, o desenvolvimento da democracia burguesa é mais provável que leve ao neofascismo do que ao socialismo. Ele

\footnotetext{
${ }^{17}$ Por exemplo, quando o indivíduo não quer reduzir sua sexualidade ao masculino ou ao feminino, ou determinar a família como composta do pai, mãe e filhos quando sua realidade é distinta disso.

\begin{tabular}{|c|c|c|c|c|}
\hline Gevista Dialectus & Ano 8 & n. 14 & Janeiro-Julho 2019 & p. 15-33 \\
\hline
\end{tabular}
}


mantém que na democracia burguesa há manipulação de mentes. Seguindo seu escrito "Repressive Tolerance" (1965), ele afirma:

\begin{abstract}
Moreover, the people are manipulated, brainwashed; the media, practically their only source of information, reflect and express government interests and policies - or rather those of the capitalist Establishment, which does not exclude some criticism within limits (Marcuse, 2001, p. 169).
\end{abstract}

Citando Freud, Wilhelm Reich, Erich Fromm, e sua própria interpretação da psicanálise, Marcuse percebe que os indivíduos estão se tornando mentalmente doentes. Para ele, as pessoas são masoquistas por apoiarem o fascismo ou um Estado de Guerra. ${ }^{18}$ De acordo com ele ${ }^{19}$ a sociedade não apenas regra sobre o princípio de prazer, mas também sobre o instinto (Triebe) de morte. Freud também escreveu sobre isso em $\mathbf{O}$ mal-estar na civilização (1927). Os indivíduos têm necessidade de uma válvula de escape para sua acumulação de energia, como sexo ou violência. A sociedade governa esta válvula, especialmente sobre violência e agressão, com a administração de esportes, guerras e crimes. As pessoas sofrem sob as regras da sociedade. As pessoas convivem todo dia com violência, pobreza, destruição, doença, morte e roubo; e tudo isso aparece como banal. Os indivíduos parecem não se importar sobre o que está acontecendo ao redor delas, isolando-se do resto do mundo. Isso poderia levar ao fascismo, na medida em que os indivíduos começam a olhar os outros com preconceito. ${ }^{20}$ Eles se tornam cada vez mais conservadores na medida em que olham para o mundo exterior e para os estrangeiros e diferentes como uma ameaça. Assim, eles apoiam regras, leis e políticas conservadoras. Na democracia totalitária, "o povo vota livremente em seus governantes, mesmo quando não está em questão manter ou conseguir um emprego - eles se identificam com seus governantes." (Marcuse, 2001, p. 170) Mesmo se eles sabem que seus governantes não são administradores honestos, ainda podem confiar neles. Aceitam a corrupção dentro do Estado enquanto continuam recebendo suas mercadorias e benefícios.

Após An Essay on Liberation (1969), Marcuse publicou Counterrevolution and Revolt (1972), demonstrando sua preopação com a situação aberta da contrarrevolução. A

18 "The mental structure involved here is the sadomasochistic character. Erich Fromm, following Freud, has developed this concept in sociopsychological terms (Studien über Autorität und Familie, ed. Max Horkheimer, Paris, Alcan, 1936, pp. 77-136. See also, Fromm, Escape From Freedom, New York, Rinehart and Co., 1941).” (Marcuse, 2001, p. 170).

19 Eros and civilization (1955) and Aggressiveness in Advanced industrial Society (1967).

20 Para mais discussões sobre o preconceito ver Stephen J. Bronner, The Bigot -Why Prejudice Still Persists. New Haven e Londres, Yale University, 2014.

\begin{tabular}{|c|c|c|c|c|}
\hline Govista Dialectus & Ano 8 & n. 14 & Janeiro-Julho 2019 & p. $15-33$ \\
\hline
\end{tabular}


eleição de Nixon estava nesse horizonte, assim como Margaret Thatcher na Inglaterra, que inauguraram o período do neoliberalismo. Tratou-se de um período de endurecimento também interno, tanto do ponto de vista econômico quanto cultural. Charles Reitz comenta:

\begin{abstract}
Nonetheless, it was Marcuse who, forty years ago, first warned of the global economic and cultural developments that are now much more obvious given capitalism's crescendo of economic failures since 2008. Political and philosophical tendencies that are often referred to as "neoliberalism" and/or "neo-conservatism" in much analytical work today, Marcuse clearly understood back then as organized counterrevolution (Marcuse 1972) (Reitz In Jansen e Reitz, 2015, 96).
\end{abstract}

Nesse mesmo texto, Reitz mostra com dados como o poder aquisitivo dos trabalhadores estadunidenses diminuiu nos últimos 50 anos. O comentário feito é feito em cima do texto das palestras de Marcuse em Vincennes em 1974. Entre outros pontos, Marcuse critica o que viria a ser o processo de globalização e a chamada sociedade pós-industrial. Embora esse processo tenha se completado muito tempo após a morte de Marcuse, sua visão é certeira ao criticar a terceirização dos trabalhadores. Diversas empresas norte-americanas apostaram em produzir suas mercadorias na China e em outros países asiáticos, devido aos baixos custos, inclusive de mão de obra. O reflexo disso foi o declínio da industrialização nos EUA, que passou a ter uma predominância de trabalhadores de serviço e agropecuária. Certamente, indústrias estratégicas, como comunicações e militar, foram preservadas. O declínio da industrialização desarticulou mais ainda movimentos sindicais de trabalhadores, o que facilitou mais os ataques do governo.

Marcuse também discute o papel da oposição. A resistência surge da necessidade dos indivíduos, necessidade biológica inclusive. Marcuse salientava o papel da Grande Recusa e da sensibilidade dos indivíduos. Assim, os negros iniciaram no final dos anos 1950 um movimento por direitos civis; as mulheres recolocam suas pautas; homossexuais iniciaram na década de 1970 seu movimento por reconhecimento. Muitos desses movimentos foram reprimidos violentamente. Em parte, eles poderiam ser caracterizados como revoltas na medida em que suas pautas eram específicas, havia dificuldade de diálogo entre eles, e não havia uma organização propriamente revolucionária.

Em seu livro de 1972, Marcuse critica a esquerda por seu "marxismo petrificado", isto é, a esquerda ainda mantinha práticas padronizadas do início do século $\mathrm{XX}$ e uma interpretação dogmática da teoria. Na medida em que o capitalismo muda para se adaptar a suas crises cíclicas e sobreviver, o movimento marxista deveria também renovar suas críticas. A

\begin{tabular}{|c|c|c|c|c|}
\cline { 2 - 5 } Govista & Ano 8 & n. 14 & Janeiro-Julho 2019 & p. $15-33$ \\
\hline
\end{tabular}


configuração tecnológica, com o uso da automação, a pós-industrialização, globalização, ressignificaram o papel dos trabalhadores no capitalismo tardio. Questões como o papel da mídia, a indústria cultural, que manipulam comportamentos, corações e mentes dos indivíduos, também deveriam ser analisados e criticados. A denominação de "marxismo cultural"21 utilizada pela esquerda tradicional (de partidos) para criticar, principalmente, os pensadores da Escola de Frankfurt expõe a própria inabilidade da esquerda tradicional em compreender o papel da cultura na manipulação ideológica do capitalismo industrial avançado. Fromm e Reich, por exemplo, afirmavam de modos diferentes que não é possível entender o fascismo apenas do ponto de vista econômico ou político, também seria necessário pensa-lo do ponto de vista psicológico, e poderia ser acrescentado do ponto de vista cultural. Assim, a ascensão de Hitler e Mussolini ao poder teve a ver com uma totalidade de aspectos autoritários da sociedade alemã e italiana e a questão da consciência é fundamental para esse entendimento. A esquerda tradicional também teve dificuldades em acompanhar movimentos novos como os mencionados de negros, mulheres, homossexuais, e também o movimento ecológico. Dado seu enfraquecimento ou ausência a direita e a extrema direita cresceram.

Em 2011, a Primavera Árabe parecia ser uma nova luz a movimentos de libertação, assim como o movimento Occupy em Wall Street. Grécia, Turquia, Brasil, entre outros países, experimentaram revoltas pela libertação, pela exigência de reconhecimento e direitos. Esses movimentos utilizaram-se de tecnologias como as redes sociais. Desenvolveram um processo de solidariedade global, que se poderia aproximar do conceito de Eros effect que Katsiaficas ${ }^{22}$ desenvolveu para descrever os movimentos de 1968. Essas revoltas foram descritas por Marcuse como consciência anticapitalista, mesmo que inconsciente.

\footnotetext{
The result of the ever more explosive contradiction is the gradual development of what we may call an anti-capitalist consciousness; the development of anti-capitalist consciousness and of an anti-capitalist mental structure, unconscious, among the population in the metropoles, a consciousness still largely unorganized, spontaneous, without definite goals, but, in any case, the consciousness, and instincts, drives, 'compulsions,' which very definitely come into conflict with the operational values required to sustain the capitalist system (Marcuse In Jansen e Reitz, 2015, p. 56).
}

${ }^{21}$ Hoje a extrema direita também utiliza essa denominação para criticar os frankfurtianos, mas por razões diversas da esquerda tradicional.

${ }^{22}$ George Katasiaficas, Imagination of the New Left - A Global analysis of 1968. (Cambridge, Mass., South End Press, 1987)

\begin{tabular}{|l|l|l|l|l|}
\hline Govista Dialectus & Ano 8 & n. 14 & Janeiro-Julho 2019 & p. $15-33$ \\
\hline
\end{tabular}


Entretanto, ao mesmo tempo, a direita e a extrema direita logo se apropriaram das mesmas tecnologias e souberam como articular suas propostas para sua contrarrevolução contra a cessão de direitos e liberdades demandadas. Esses grupos de direita e extrema direita insuflaram o ódio contra homossexuais, negros, mulheres, imigrantes, refugiados, e contra a própria esquerda tradicional e ao marxismo em geral, acusando-os de deturpar os valores tradicionais da sociedade. São grupos conservadores, contra qualquer mudança social, que, ao defenderem seus interesses, defendem os interesses das classes dominantes.

A contrarrevolução hoje está se espalhando em todo o mundo. Reitz e Spartan chamam a atenção para o caráter predatório do capitalismo. ${ }^{23}$ A crise mundial e a ida para uma via cada vez mais direitista e conservadora resultam do aumento da exploração e acumulação capitalista. Na medida em que os $99 \%$ da população querem acessar sua partilha real nesta sociedade, a repressão surge para suprimi-los. A guerra contra o terrorismo produziu mais terrorismo. Muitos refugiados não têm solidariedade enquanto ficam em campos isolados. Semtetos nas grandes cidades são tratados do mesmo modo. As pessoas se revoltam porque precisam. Não é algo retórico, mas um sentimento interno. Resistência é necessária, mas precisa ser organizada de tal modo que mude o modo opressivo da vida. Mais ainda: é necessário lutar contra a imposição de notícias falsas (Fake News), pós-verdade, e falso conhecimento. O fascismo se alimenta da ignorância. Chegam a criticar verdades adquiridas pela humanidade, como a questão da forma da Terra ou a evolução humana. Marcuse defende a contra-educação, que significa lutar contra a imposição de conhecimentos pré-formatados em dogmas, como religião fez durante o período medieval. Os fundamentalismos exigem um conhecimento baseado exclusivamente em seu livro, seja a Bíblia, o Corão ou outro. Nega-se o pensamento crítico. Ataca-se os professores. Contra isso, Marcuse acredita no papel de uma educação crítica e humanista, além do adestramento técnico profissional da educação unidimensional. A educação crítica não é impositiva, ao contrário, visa os indivíduos a pensarem sobre suas próprias condições. Visa a história humana, mostrando o lado dos vencidos, dos oprimidos. Visa a reflexão sobre a própria realidade. Trata-se de uma tarefa difícil na medida em que a educação ocorre no processo social, não apenas na escola, pois a mídia tem um papel totalizante,

${ }^{23}$ Reitz, Charles and Spartan, Stephen. "The Political Economy of Predation and Counterrevolution: Recalling Marcuse on the Radical Goals of Socialism" In Reitz, Charles (ed.) Crisis and

Commonwealth: Marx, Marcuse, McLaren. Lathan, Boulder, Nova York, Toronto, Plymouth (UK), Lexington Books, 2013. pp. 19-42.

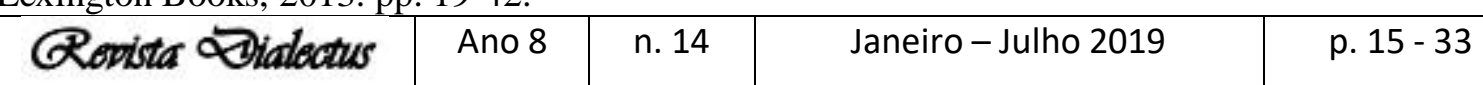


mas é uma tarefa a ser feita, como resistência. Diante dos horrores da contrarrevolução, os intelectuais deveriam tomar uma posição. Cito, Marcuse:

\begin{abstract}
Today the real possibilities of human freedom are so real and the crimes of the society which prevents their realization are so blatant that the philosopher, the educator can no longer avoid taking sides, and that means alliance, solidarity with those who are no longer capable and no longer willing to have their future, to have their existence determined and defined by the requirements of the status quo. ${ }^{24}$
\end{abstract}

Mais ainda, se resistência e mudança social podem ser feitas, Marcuse responde: “Ainda pode ser feito. Se você se sente desesperado, desesperançado, apático, então, você desistiu para a propaganda do establishment. Cabe a você negar esta propaganda!”.

IT CAN STILL BE DONE. If you feel only despair, hopelessness, apathy, then, you have given in to Establishment propaganda. It is still up to you to deny this propaganda! ${ }^{25}$

\title{
Referências:
}

ANDERSON, Kevin e ROCKWELL, Russell. (eds.) The DunayevskayaMarcuse-Fromm Correspondence 1954-1978. Dialogues on Hegel, Marx and Critical Theory. Lanham, Boulder, Lexington, New York, Toronto, Plymouth (UK), Lexington Books, 2012.

ARONOWITZ, Stanley, “The Unknown Marcuse” In: Social Text 58, Vol. 17, No.1, Spring 1999. 133-154.

BENJAMIN, Walter. “Theories of German Fascism” In New German Critique, trans. Jerolf Wikoff, Spring 1979, n. 17, pp. 120-128.

Illuminations. Trans. Harry Zohn. Introduction by Hannah Arendt. Preface Leon Wiseltier. New York, Schocken Books, 1968.

BERNAYS, Edward. Propaganda, Liveright, 1928.

BRONNER, Stephen J. The Bigot -Why Prejudice Still Persists. New Haven and London, Yale University, 2014.

${ }^{24}$ Marcuse, "Beyond One-dimensional Man" In: Herbert Marcuse. Towards a Critical Theory of Society. Douglas Kellner (ed) Nova York e Londres, Routledge, 2001. p. 119.

${ }^{25}$ Marcuse, Herbert. "Lecture on Higher Education and Politics, Berkeley, 1975" In Kellner et alii. Marcuse's Challenge to Education. Lathan, Boulder, Nova York, Toronto, Plymouth (UK), Rowman e Littlefield, 2009. p. 43.

\begin{tabular}{|c|c|c|c|c|}
\hline Q Rovista Dialectus & Ano 8 & n. 14 & Janeiro-Julho 2019 & p. $15-33$ \\
\hline
\end{tabular}


CHOMSKY, Noam. Deterring Democracy. Londres e Nova York, Verso, 1991.

FROMM, Erich. Fear of Freedom. (Escape from Freedom). Londres e Nova York, Routledge, 2001 (1942).

JANSEN, Peter-Erwin and REITZ, Charles. (eds) Herbert Marcuse's 1974 Paris Lectures at Vicennes University from Marcuse Archives. Global Capitalism and Radical Opposition. Introduction by Sarah Surak and afterwords by Douglas Kellner. Salisbury University, Maryland, USA, 2015.

KATASIAFICAS, George, Imagination of the New Left - A Global analysis of 1968. Cambridge, Mass., South End Press, 1987.

KELLNER, Douglas. Media Culture. Cultural Studies, Identity and Politics between the Modern and Postmodern. London and New York, Routledge, 1995.

KELLNER, LEWIS, PEIRCE AND CHO (eds), Marcuse's Challenge to Education. Lanham, Boulder, Nova York, Toronto, Plymouth, UK, Rowman \& Littlefield Publishers, Inc., 2009.

MALEY, Terry. "Human Emancipation and The Historical Fate Bourgeois Democracy" In.: MALEY, Terry (ed.) One-dimensional Man 50 years on: The Struggle Continues, Nova Scotia, Manitoba, Fernwood Publishing, 2017. pp. 209-227.

MARCUSE, Herbert. Technology, War and Fascism. Douglas Kellner (ed). Nova York e Londres, Routledge, 1998, 217. (Collected Papers, vol.1).

Towards a Critical Theory of Society. Douglas Kellner (ed), Nova York e Londres, Routledge, 2001. (Collected Papers, vol. 2).

. The New Left and The 1960s. Douglas Kellner (ed.) Nova York e Londres, Routledge, 2005. (Collected Papers, vol 3).

Philosophy, Psychoanalysis and Emancipation. Douglas Kellner e Clayton Pierce (eds.) Nova York e Londres, Routledge, 2011. (Collected Papers, vol 5).

Tecnologia, Guerra e Fascismo. Organização e Introdução de Douglas Kellner. Tradução Maria Vidal Borba. São Paulo, EdUnesp, 1999.

Counterrevolution and Revolt. Boston, Beacon Press, 1972.

\begin{tabular}{|l|c|c|c|c|}
\cline { 2 - 4 } & Ano 8 & n. 14 & Janeiro-Julho 2019 & p. $15-33$ \\
\hline
\end{tabular}


. O homem unidimensional - Estudos da ideologia da sociedade industrial avançada. Trad. Robespierre de Oliveira, Rafael Cordeiro Silva, Deborah Antunes. São Paulo, Edipro, 2015.

Eros and Civilization. Boston, Beacon Press, 1955.

"Repressive Tolerance", In Wolff, Robert P.; Moore Jr., Barrington; and Marcuse, Herbert. A Critique of Pure Tolerance. Boston, Beacon Press, 1965.

REITZ, Charles. Celebrating Herbert Marcuse's One-Dimensional Man: Deprovicialization and the Recovery of Philosophy. Nova York, Columbia University, 2014.

REITZ, Charles (ed.) Crisis and Commonwealth: Marx, Marcuse, McLaren. Lathan, Boulder, Nova York, Toronto, Plymouth (UK), Lexington Books, 2013.

WOLIN, Sheldom. Politics and Vision. Continuity and Innovation in Western Political Thought. Princeton e Oxford, Princeton University Press, 1960, 2004. (edição expandida).

\begin{tabular}{|l|c|c|c|c|}
\cline { 2 - 4 } & Ano 8 & n. 14 & Janeiro-Julho 2019 & p. $15-33$ \\
\hline
\end{tabular}

